\title{
外頸静脈を含めた新広頸筋皮弁法
}

一頸部郭清術の併用と生着率に関する Farr の変法との比較検討一

$\begin{array}{lrll}\text { 斎藤 } & \text { 等 } \cdot \text { 津田 } & \text { 豪太・藤枝 } & \text { 重治 } \cdot \text { 真鍋 恭弘 } \\ \text { 大坪 } & \text { 俊雄 } \cdot \text { 本多 } & \text { 徳行・森 } & \text { 繁人 } \cdot \text { 五十嵐 充 }\end{array}$

\section{A New Version of Platysma Myocutaneous Flap Including the External Jugular Vein ; A Comparison with Farr's Modified Method with Special References to the Viability of Flaps and Combinations with Neck Dissection}

\author{
Hitoshi Saito, Gota Tsuda, Shigeharu Fujieda, Yasuhiro Manabe, \\ Toshio Ohtsubo, Noriyuki Honda, Shigehito Mori and Mitsuru Igarashi \\ (Fukui Medical School)
}

\begin{abstract}
A new version of the platysma myocutaneous flap, which includes the external jugular vein and the preserved facial artery, was utilized in eight patients. The viable area of transferred skin was $64 \%$ on average. This rate was statistically better than that in 46 cases using Farr's modification with conservative or radical neck dissection, and was almost the same viability rate as that in cases without neck dissection. It was, therefore, concluded that this new version is a useful local flap especially for intra-oral defects measuring $30 \sim 40 \mathrm{~cm}^{2}$.
\end{abstract}

Key words: platysma myocutaneous flap, new version, neck dissection

はじめに

筋皮弁の概念を考えずに臨床応用されていた 頸部島状皮弁は1)2)，Futrell らによって筋皮弁 の概念が導入され，広頸筋皮弁と命名された ${ }^{33}$. その後, この皮弁に対する血行支配が詳細に報 告されている4) 6)，それらによると，広頸筋皮 弁は顔面動脈の願下部枝により支配されている ため, 標準的頸部郭清術ではこれらの血管を切 断する. したがってこの皮弁は, 頸部郭清術と 併用する場合適応ではないとしている。しかし，
顔面動静脈を切断しても，約 $40 \%$ の皮弁は壊死 に陥るが7)，瘦孔などの合併症は起こらないと 報告されているし ${ }^{899)}$ ，われわれも同様の経験 をしている。

われわれは，広頸筋皮弁を作るために表皮を 保存する Farr の変法10111)を中心に，53例に施 行してきた.これまで顔面動静脈を切断し, 頸 部郭清術を併用しても, 重大な合併症を経験し ていない。しかし, 表皮はゆっくりと壊死に陥 り, 線維組織に置換されて治癒する症例が多く, 
完全生着例は少なかったそそこで完全生着率の 向上を意図して, 顔面動脈を顎下腺から剥離温 存し, 外頸静脈を皮弁につける新変法を考案し, 8 例に施行したところ, 良好な結果を得た。

本論文では，この新变法と従来法における， 生着率, 頸部郭清術を併用した場合としない場 合の治瘉状態など比較検討し，興味ある結果を 得たので報告する。

\section{手術術式と症例}

有茎皮弁の茎部を下顎の側方に置く方法と， 正中に置く方法の 2 法がある.

1. 外側頸部島状皮弁一Farr の変法10111) -

図 1 に示した Farr の変法を1988年までに50 例に用いた。剝離保存した表皮は最終皮膚縫合 に利用した。この術式では, 皮弁に外頸静脈を
含めていない，根治的頸部郭清術を併用した 23 例の場合にも（表 1)，保存的頸部郭清術を併 用した23例の場合にも（表 2), 全例顔面動静 脈を切断して顎下腺を合併摘出し，根治性を高 めるとともに皮弁の口腔内への通路を確保した. 4 例には頸部郭清術を併用せず，顎下腺も温存 した（表 3 ）.

2. 外側頸部島状皮弁一新広頸筋皮弁法一 図 2 に示すごとく，上皮の剥離を皮弁基部の 中央で行い両側に温存し最終皮膚縫合に利用し， 裏面に外頸静脈を付着させ, 顔面動脈は顎下腺 から丁寧に剥離保存した。 なお, 保存的頸部郭 清術の場合には顔面静脈も可及的に保存した. 本法を1989年以来 8 例に用いた（表 4 ）.

表 1 根治的頸部郭清術併用例

\begin{tabular}{clcccc}
\hline \hline 症例 & 原発部位 & $\begin{array}{c}\text { 皮弁サイズ } \\
(\mathrm{cm})\end{array}$ & 放射線療法 & $\begin{array}{c}\text { 皮膚生着面積 } \\
(\%)\end{array}$ & 合併症 \\
\hline 1 & 口腔底 & $6.0 \times 4.0$ & - & 90 & なし \\
2 & 歯肉 & $6.0 \times 5.0$ & 後 $60 \mathrm{~Gy}$ & 0 & なし \\
3 & 歯肉 & $6.0 \times 5.0$ & 後 $53 \mathrm{~Gy}$ & 0 & なし \\
4 & 歯肉下買 & $6.0 \times 5.0$ & - & 0 & なし \\
5 & 舌 & $6.0 \times 5.0$ & 後 $60 \mathrm{~Gy}$ & 0 & なし \\
6 & 口腔底 & $6.0 \times 5.0$ & 後 $60 \mathrm{~Gy}$ & 0 & なし \\
7 & 扁桃 & $4.0 \times 3.0$ & 前 $32 \mathrm{~Gy}$ & 0 & なし \\
8 & 口腔底 & $6.0 \times 5.0$ & 前 $30 \mathrm{~Gy}$ & 0 & なし \\
9 & 扁桃 & $6.0 \times 4.0$ & 後 $60 \mathrm{~Gy}$ & 70 & なし \\
10 & 扁桃 & $6.0 \times 5.0$ & - & 0 & なし \\
11 & 舌 & $6.5 \times 4.5$ & 後 $64 \mathrm{~Gy}$ & 0 & なし \\
12 & 口腔底 & $6.0 \times 4.5$ & - & 0 & なし \\
13 & 口腔底 & $6.0 \times 4.5$ & 前 $50 \mathrm{~Gy}$ & 0 & 瘻孔（十)，自然閉鎖 \\
14 & 扁桃 & $6.5 \times 3.5$ & 後 $60 \mathrm{~Gy}$ & 0 & なし \\
15 & 扁桃 & $5.0 \times 4.0$ & 後 $40 \mathrm{~Gy}$ & 0 & なし \\
16 & 舌 & $6.0 \times 4.0$ & 前 $39 \mathrm{~Gy}$ & 0 & なし \\
17 & 歯肉 & $5.0 \times 4.0$ & - & 0 & なし \\
18 & 舌根 & $5.0 \times 4.0$ & 後 $60 \mathrm{~Gy}$ & 0 & なし \\
19 & 舌 & $6.0 \times 5.0$ & 後 $60 \mathrm{~Gy}$ & 0 & なし \\
20 & 舌 & $5.5 \times 3.5$ & 後 $60 \mathrm{~Gy}$ & 0 & なし \\
21 & 舌 & $5.0 \times 4.5$ & 後 $60 \mathrm{~Gy}$ & 0 & なし \\
22 & 舌 & $6.0 \times 4.0$ & - & 0 & なし \\
23 & 扁桃 & $5.5 \times 4.0$ & 後 $60 \mathrm{~Gy}$ & 0 & なし
\end{tabular}




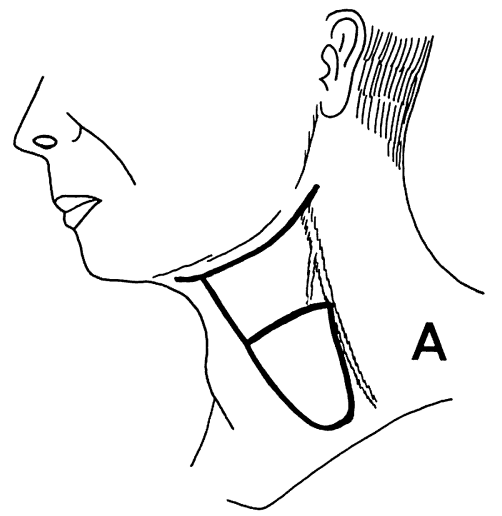

A. 皮切デザイン

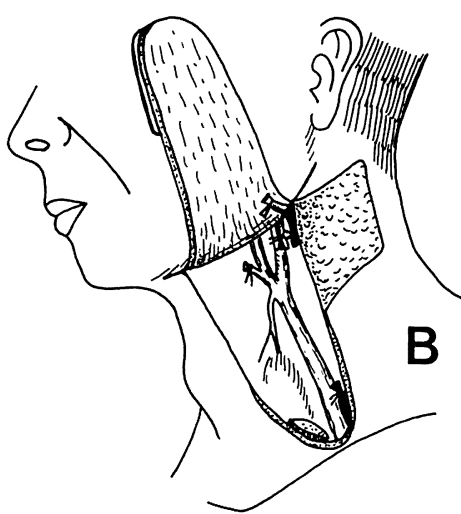

B．皮弁を挙上したところ

図 1 Farr の变法

表 2 保存的頸部郭清術併用例

\begin{tabular}{|c|c|c|c|c|c|}
\hline 症例 & 原発部位 & $\begin{array}{c}\begin{array}{c}\text { 弁サイズ } \\
(\mathrm{cm})\end{array} \\
\end{array}$ & 放射線療法 & $\begin{array}{c}\text { 皮膚生着面積 } \\
(\%)\end{array}$ & 合併症 \\
\hline 1 & 口腔底 & $6.0 \times 4.0$ & - & 0 & なし \\
\hline 2 & 扁桃 & $6.0 \times 3.5$ & 後 $60 \mathrm{~Gy}$ & 100 & なし \\
\hline 3 & 舌根 & $5.5 \times 4.0$ & 前 $30 \mathrm{~Gy}$, 後 $30 \mathrm{~Gy}$ & 0 & なし \\
\hline 4 & 舌 & $5.5 \times 4.0$ & - & 50 & なし \\
\hline 5 & 舌 & $4.0 \times 3.5$ & 後 $60 \mathrm{~Gy}$ & 0 & なし \\
\hline 6 & 舌 & $5.0 \times 3.5$ & 後 $60 \mathrm{~Gy}$ & 50 & なし \\
\hline 7 & 舌 & $6.0 \times 4.5$ & 前 $30 \mathrm{~Gy}$, 後 $30 \mathrm{~Gy}$ & 90 & なし \\
\hline 8 & 口腔底 & $6.0 \times 4.5$ & - & 0 & なし \\
\hline 9 & 歯肉 & $5.0 \times 3.5$ & 前 $30 \mathrm{~Gy}$ & 0 & なし \\
\hline 10 & 口腔底 & $6.5 \times 4.5$ & 後 $56 \mathrm{~Gy}$ & 50 & なし \\
\hline 11 & 口腔歯肉 & $4.5 \times 4.0$ & 後 $60 \mathrm{~Gy}$ & 0 & なし \\
\hline 12 & 扁桃 & $4.5 \times 4.0$ & 後 $62 \mathrm{~Gy}$ & 20 & なし \\
\hline 13 & 口腔底 & $5.0 \times 4.0$ & 後 $60 \mathrm{~Gy}$ & 0 & なし \\
\hline 14 & 舌 & $5.0 \times 4.0$ & 前 $60 \mathrm{~Gy}$ & 0 & なし \\
\hline 15 & 舌根 & $4.0 \times 4.0$ & 後 $61 \mathrm{~Gy}$ & 0 & なし \\
\hline 16 & 舌 & $4.5 \times 3.5$ & - & 90 & なし \\
\hline 17 & 口腔底 & $4.0 \times 3.0$ & - & 0 & 瘦孔 $(+)$, 自然閉鎖 \\
\hline 18 & 舌 & $5.0 \times 4.5$ & - & 0 & なし \\
\hline 19 & 舌 & $5.5 \times 4.5$ & 後 $61 \mathrm{~Gy}$ & 0 & なし \\
\hline 20 & 舌 & $6.0 \times 4.0$ & 後 $60 \mathrm{~Gy}$ & 100 & なし \\
\hline 21 & 歯肉 & $6.0 \times 4.0$ & 後 $60 \mathrm{~Gy}$ & 0 & なし \\
\hline 22 & 舌 & $5.0 \times 4.0$ & 後 $60 \mathrm{~Gy}$ & 0 & なし \\
\hline 23 & 舌 & $5.0 \times 5.0$ & 後 $60 \mathrm{~Gy}$ & 0 & なし \\
\hline
\end{tabular}

平均士標準偏差 $=23.9 \pm 37.5$ 


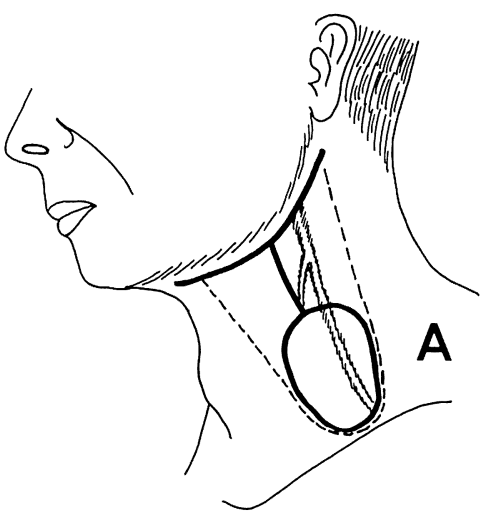

A. 皮切デザイン

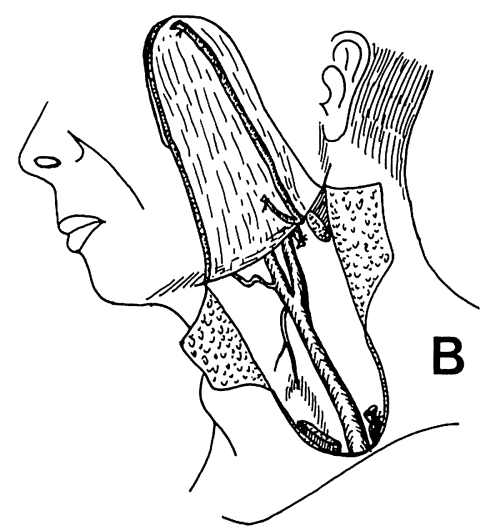

B．皮弁を挙上したところ

図 2 新広頸筋皮弁法

表 3 頸部郭清術非併用例

\begin{tabular}{|c|c|c|c|c|c|}
\hline 症例 & 原発部位 & $\begin{array}{c}\text { 皮弁サイズ } \\
(\mathrm{cm})\end{array}$ & 放射線療法 & $\begin{array}{c}\text { 皮膚生着面積 } \\
(\%)\end{array}$ & 合併症 \\
\hline 1 & 歯 肉 & $6.0 \times 5.0$ & 前 $60 \mathrm{~Gy}$ & 90 & 凄孔 $(+), 2$ 次手術閉鎖 \\
\hline 2 & 頓粘膜 & $4.0 \times 3.0$ & - & 90 & なし \\
\hline 3 & 頓粘膜 & $5.0 \times 4.0$ & 前 $60 \mathrm{~Gy}$ & 70 & なし \\
\hline 4 & 頓粘膜 & $4.0 \times 3.0$ & - & 100 & なし \\
\hline
\end{tabular}

平均士標準偏差 $=87.5 \pm 12.6$

表 4 外側頸部島状皮弁 一新広頸筋皮弁法一

\begin{tabular}{|c|c|c|c|c|c|c|}
\hline 症例 & 原発部位 & $\begin{array}{c}\text { 皮弁サイズ } \\
(\mathrm{cm})\end{array}$ & 放射線療法 & $\begin{array}{c}\text { 友膚生着面積 } \\
(\%)\end{array}$ & 合併症 & 頸部郭清術 \\
\hline 1 & 舌 & $5.0 \times 3.5$ & - & 100 & なし & 右根治的 \\
\hline 2 & 舌 & $5.0 \times 3.0$ & - & 30 & なし & 右根治的 \\
\hline 3 & 扁桃 & $5.0 \times 4.0$ & - & 70 & なし & 右保存的 \\
\hline 4 & 口腔底 & $4.5 \times 3.5$ & - & 50 & なし & 左保存的 \\
\hline 5 & 口腔底 & $5.0 \times 4.0$ & - & 100 & なし & 右保存的 \\
\hline 6 & 扁桃 & $6.0 \times 4.0$ & 後 $60 \mathrm{~Gy}$ & 100 & なし & 左保存的 \\
\hline 7 & 舌 & $5.0 \times 4.0$ & - & 0 & なし & 右保存的 \\
\hline 8 & 臼後三角 & $6.0 \times 4.0$ & 後 $52 \mathrm{~Gy}$ & 60 & なし & なし \\
\hline
\end{tabular}

平均士標準偏差 $=63.8 \pm 36.6$

表 5 正中頸部島状皮弁例

\begin{tabular}{ccccccc}
\hline \hline 症例 & 原発部位 & $\begin{array}{c}\text { 皮弁サイズ } \\
(\mathrm{cm})\end{array}$ & \begin{tabular}{c} 
放射線療法 \\
\hline 1
\end{tabular} 前口腔底 & $\begin{array}{c}6.0 \times 6.0 \\
\text { 膚生着面積 } \\
(\%)\end{array}$ & 合併症 & 頸部廟清術 \\
\hline 2 & 前口腔底 & $6.0 \times 5.0$ & - & 0 & なし & 左保存的 \\
3 & 前口腔底 & $5.0 \times 5.0$ & - & 70 & なし & 両保存的 \\
\end{tabular}


3. 正中頸部島状皮弁法

正中願下部に有茎部をもつ Desprez らの方 法12)を，上皮を保存するように修飾して用い た。これらの例には，片側あるいは両側の保存 的頸部郭清術を併用した。本法を 3 例に用いた (表 5 ).

\section{結 果}

それぞれの方法の, 原発部位, 皮弁サイズ, 放射線療法, 皮虐生着面積, 合併症, などを表 $1 〜 5$ に記載した.

移植皮膚上皮の平均生着面積は, 根治的頸部 郭清術併用 $(\mathrm{N}=23)$ で7.0\%, 保存的頸部郭清 術併用 $(\mathrm{N}=23)$ で23.9\%, 頸部郭清術非併用 $(\mathrm{N}=4)$ で $87.5 \%$ ，新広頸筋皮弁法 $(\mathrm{N}=8)$ で 63.8\%であった。

各群に打ける皮膚生着率の有意差の有無を対 応のない $\mathrm{t}$ 検定で行った. 根治的と保存的頸部 郭清術の併用による皮膚生着率には有意差はな かった. 根治的頸部郭清術併用と新变法の比較 では, 危険率 $1 \%$ 以下の有意差をもって, 保存 的頸部郭清術併用との比較では $5 \%$ 以下の有意 差をもって，新変法の皮膚生着率が優れていた. しかし, 頸部郭清術非併用群とは有意差はなく， 同等の生着率と解釈できた。

\section{考察}

外頸静脈を皮弁に付け顔面動脈を保存する新 広頸筋皮弁法の生着率の良いことが，例数はま だ少ないが証明された. 外頸静脈を皮并に付着 保存しても，それは逆行性の静脈循環ではある が，その有効性が観察されたわけである13)。 た，この結果は顔面動脈を保存してもそれが直 接の軸血管ではないが，間接的に有効なことを 証明している。しかし個体差が大きいのは直接 の軸血管でないところが関係しているといえる.

皮膚の完全生着は少なくても, 瘦孔などの重 大な合併症が発生しないことは，今回の61例全 体の結果からも明らかである。この理由として， 皮膚は壊死となっても広頸筋は生着するとの見 解と, もら一つは徐々に進行する壊死のため線 維組織によって置換されることが考兄られる.

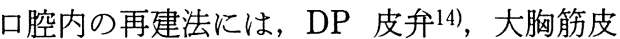
弁15) などの有茎皮弁の他に，遊離皮弁16)，遊離 空腸 17)，さらには下䫇の合併切除に対する骨付 き皮弁法18119)などがある。しかし，以上の再 建方法は拡大手術には適するが，通常頻度の多 い $30 \sim 40 \mathrm{~cm}^{2}$ 位の欠損にはかえってかさばっ て不適当である.今回の新広頸筋皮弁法は，局 所皮弁のため侵襲も少なく簡単で，小〜中欠損 に対しては有効な方法といえる。

\section{まとめ}

外頸静脈を皮弁に付け，顔面動脈を保存する 新広頸筋皮弁法を 8 例に用いた結果, 生着皮膚 面積は平均 $64 \%$ であった。これらと, 従来の頸 部郭清術を併用した Farr の変法の50例と比較 したところ，有意差をもって生着率が優れてお り，頸部郭清術を併用しない場合の生着率と同 等の結果を得た。以上より, 本新变法は 30 $40 \mathrm{~cm}^{2}$ 位の口腔内の欠損には大変有効な局所 皮弁であるといえる.

\section{参考文献}

1) Edgerton MT and Desprez JD : Reconstruction of the oral cavity in the treatment of cancer. Plast Reconstr Surg $19: 89 \sim 113,1957$.

2) Farr HW, Jean-Gilles B and Die A : Cervical island skin flap repair of oral and pharyngeal defects in the composite operation for cancer. Am J Surg $118:$ 759 763, 1969.

3) Futrell JW, Johns ME, Edgerton MT, et al : Platysma myocutaneous flap for intraoral reconstruction. Am J Surg 136 : 504 507, 1978.

4) Hurwitz DJ, Rabson JA and Futrell JW : The anatomic basis for the platysma skin flap. Plast Reconstr Surg 72 : 302 312, 1983.

5) Rabson JA, Hurwitz DJ and Futrell JW : The cutaneous blood supply of the neck ; relevance to incision planning and surgical reconstruction. Br J Plast Surg 38 : 208 219, 1985.

6) McGuirt WF, Matthews BL, Brody JA, et al : Platysma myocutaneous flap; caveats reexamined. Laryngoscope $101: 1238 \sim 1245,1991$.

7) Conley JJ, Lanier DM and Tinsley P : Platysma myocutaneous flap revisited. Arch 
Otolaryngol Head Neck Surg $112: 711 \sim 713$, 1986.

8) Coleman JJ, Nahai F and Mathes SJ : Platysma musculocutaneous flap; clinical and anatomic considerations in head and neck reconstruction. Am J Surg $144:$ 477 481, 1982.

9) Coleman JJ, Jurkiewicz MJ, Nahai F, et al : The platysma musculocutaneous flap; experience with 24 cases. Plast Reconstr Surg 72 : 315 321, 1983.

10) Saito H, Nishimura $H$, Matsui $T$, et al : Primary reconstruction by modified cervical island flap following resection of oral and pharyngeal cancer. Arch Otorhinolaryngol $221: 203 \sim 210,1978$.

11) Saito $H$ : Cervical musculocutaneous flap for intraoral lining. Grabb's Encyclopedia of Flaps Vol 1 (ed by Strauch B, Vasconez LO and HallFindlay EJ). pp 478 480, Little Brown CO, Boston, 1990.

12) Desprez JD and Kiehn CL : Methods of reconstruction following resection of anterior oral cavity and mandible for malignancy. Plast Reconstr Surg 24 : 238 249, 1959.

13) Timmons MJ : William Harvey revisited ; reverse flow through the valves of forearm veins. Lancet August 18 : 394 395, 1984.
14) Bakamjian VY : A two-stage method for pharyngoesophageal reconstruction with a primary pectoral skin flap. Plast Reconstr Surg $36:$ 173 184, 1965.

15) Ariyan $S:$ Further experiences with the pectoralis major myocutaneous flap for the immediate repair of defects from excisions of head and neck cancers. Plast Reconstr Surg $64: 605 \sim 612,1979$.

16) Soutar DS, Scheker LR, Tanner NSB, et al : The radial forearm flap; a versatile method for intraoral reconstruction. Br J Plast Surg $36: 1 \sim 8,1983$.

17) Hester RT, McConnel FM, Nahai F, et al : Reconstruction of cervical esophagus, hypopharynx, and oral cavity using free jejunal transfer. Am J Surg $140:$ 487 491, 1980.

18) Taylor GI : Reconstruction of the mandible with free composite iliac bone graft. Ann Plast Surg $9: 361 \sim 376,1982$.

19) Teot L, Bosse JP, Moufarrege R, et al : The scapular crest pedicled bone graft. J Microsurg 3 : 257 262, 1981.

$$
\left(\begin{array}{l}
\text { 別刷請求先 : 斎藤 等 } \\
\boldsymbol{T} 910-11 \text { 福井県吉田郡松岡町下合月 23-3 } \\
\text { 福井医科大学耳鼻咽喉科学教室 }
\end{array}\right)
$$

